DOI 10.18551/rjoas.2019-12.05

\title{
SOCIO-ECONOMIC ANALYSIS OF MODERN RICE PRODUCTION TECHNOLOGIES IN GHANA
}

\author{
Owusu Rebecca \\ Department of Agricultural Economics and Extension, University of Cape Coast, Ghana \\ E-mail: rebecca.owusu@ucc.edu.gh
}

\begin{abstract}
Many development economists have perceived introduction of new agricultural technologies as vital for improving agricultural productivity growth in Sub-Saharan Africa. However, adoption and use of these technologies have not been a complete success due to slow adoption rates. In this paper, a socio-economic analysis of a recent technology introduced in Ghana is conducted to provide vital information for policy makers. Specifically, an average treatment effects framework is employed to simultaneously model adoption intensity and determinants, whiles correcting for exposure (awareness) bias. Also, the technology impacts on farm productivity and income are explored using an endogenous switching regression model. Using survey data on SDRP (sustainable development of rain-fed lowland rice production) adoption, the adoption intensity was estimated at $59 \%$. Also, the empirical estimates show that land quality related factors and perception of technology characteristics drive farmers' adoption decisions. SDRP adoption was also found to impact positively on farm productivity and income.
\end{abstract}

\section{KEY WORDS}

Rice, production, Ghana, policies, development.

In recent times, many SSA governments and development partners are calling for a second Green Revolution (Sanchez et al. 2009) that are based on technological developments and favorable policies that respond to a diversity of local farming systems, and well-grounded in local contexts to develop locally appropriate technological solutions (Moyo et al. 2015). As such, most of the new technologies that are introduced in SSA incorporate locally generated ideas and practices that farmers are familiar with as a means of improving adoption. One such project is the sustainable development of rain-fed lowland rice production (SDRP) technology implemented in Ghana to boost domestic rice production. The SDRP technology is jointly funded by the Japanese Government through Japan International Development Agency (JICA) and the Ghana Government through Ministry of Food and Agriculture (Mumuni \& Oladele 2012). The aim of SDRP technology was to increase productivity and profitability of rice producing households by addressing challenges related to agronomic practices and water conservation in lowland rice production system. Conservative estimates indicate that Ghana has over 5 million hectares of unexploited rain-fed lowlands which could be developed to increase local rice production and decrease imports, the reason for investing in the SDRP technology to boost productivity. The technology has three components: land development, rice cultivation and extension practices.

It, therefore, suffices to ask whether modifications in the design and introduction of new agricultural technologies have improved their adoption. The answer to this question is mainly empirical and requires the application of robust econometric techniques to examine. It is considering this that this study seeks to evaluate the SDRP technology regarding the adoption rates, drivers of adoption and impacts on productivity and incomes. As Oster and Thornton (2009) posited evaluating new agricultural technologies is relevant to identify adoption patterns, support adopters to ensure discontinuity in adoption and to device new desirable methods of promoting new agricultural technologies. Most studies that have examined adoption rates of new agricultural technologies and impacts have mainly done so using standard logit and probit models, as well as propensity score matching (PSM) to account for selection bias (Zakaria et al. 2016). 
Diagne and Demont (2007) argue that the standard logit and probit models applied in most empirical studies to derive adoption rates and examine drivers of adoption have a narrow theoretical base as they implicitly assume a homogenous population of potential adopters and no active information search (Kabunga et al. 2012). Such studies yield biased estimates of both adoption rates as well as determinants of adoption when applied to a population that is not fully aware of the technology (Simtowe et al. 2016b). In addition, the application of propensity score matching to account for selection bias in impact assessment studies, as is often applied in the impact assessment literature is inadequate because of a possible systematic differences between adopters and non-adopters outcomes even after conditioning (Abdulai \& Huffman, 2014).

In this paper, the average treatment effect framework (Diagne \& Demont 2007), which draws from the modern evaluation theory in the treatment effects literature is employed to evaluate adoption rate of the SDRP technology. The average treatment effect (ATE) assumes that commonly used adoption rate estimators suffer from non-exposure or selection bias arising from the fact that farmers who have not been exposed to a new technology cannot adopt it and corrects for this through a simultaneous estimation of awareness and adoption of the technology. The approach to estimate adoption rate in this paper is in keeping with previous studies (Simotowe et. al. 2016a; Diagne \& Demont 2007; Kathage et. Al 2016). In addition, an endogenous switching regression model is used to examine the impact of the SDRP technology (Kassie et al. 2013; Kassie et al. 2015; Manda et al. 2016; Awotide et al. 2015; Alene \& Manyong 2007; Abdulai, 2016b).

The endogenous switching regression (ESR) model is preferred to the PSM approach because systematic differences between adopters and non-adopters' outcomes resulting from unmeasured characteristics are accounted for (Abdulai \& Huffman 2014; Smith \& Todd 2005). In the impact evaluation literature, two approaches are often adopted to estimate the ESR model: The full maximum likelihood estimation (FIML) and the two-stage approaches (Maddala 1986). Lokshin and Sajaia (2004) argue that the two-step approach generates heteroscedastic residuals and therefore cannot be consistently used to estimate standard errors of the model parameters. The FIML approach therefore dominates the empirical literature (Abdulai \& Huffman 2014; Di Falco et al. 2011), and that is what has been adopted in this study. This study contributes to providing empirical evidence of adoption rates and impact of agricultural technology adoption in a developing country using recent advances in the adoption and impact evaluation literature.

\section{ECONOMETRIC MODELLING}

Modelling farmer adoption rate using average treatment effects framework. Analyzing adoption decisions of farmers presents the question of whether every potential adopter is aware of or exposed to the technology. If potential adopters are not aware of the technology and the modelling approach does not adjust estimates for lack of awareness, observed sample adoption estimates may inconsistently represent true population parameters (Kabunga et al. 2012). Previous studies identified this potential bias in estimating an adoption model without accounting for exposure bias and introduced a latent variable model to address it. However, Diagne and Demont (2007) argued that the latent variable approach is inefficient because of the binary nature of the adoption outcome variable. Rather, the authors suggested the use of a counterfactual average treatment effects (ATE) framework to estimate the model.

The ATE assumes that every farmer in a population has two potential outcomes: with and without exposure or awareness of the technology. Given $N$ farmers and a binary treatment variable, $m$ (awareness status and a binary outcome variable), a farmer is described as aware of SDRP (treated) if $m=1$. Again, a farmer is referred to as unaware of SDRP if $m=0$ (untreated). For the $N$ farmers, the number of aware farmers can be denoted as $\mathrm{Ne}$. At the same time, for each farmer, an $x$-dimensional column of covariates is observed. At the aggregate level (population level), the interest is to explain exposure rates $\left(N_{e} / M\right)$, while at the individual farmer level, the focus is to explain adoption status $(\mathrm{Na} / \mathrm{M})$, 
assuming a universal adoption rate and exposure among the exposed $\left(\mathrm{Na} / \mathrm{N}_{e}\right)$ when there is an incomplete exposure (Kabunga et al. 2012).

Now, assuming an indicator variable for potential outcome, $q$, outcome with exposure, $q_{1}$, and outcome without exposure, $q_{0}, q$ can be specified as:

$$
q=m q_{1}=q_{0}(1-m)+m q_{1}=\left\{\begin{array}{l}
q_{0} \text { if } m=0 \\
q_{1} \text { if } m=1
\end{array}\right.
$$

Under incomplete exposure, the treatment effect for each farmer $i$ is the difference between adoption status if aware, and adoption status if not aware $\left(q_{1 i}-q_{0 i}\right)$ or aggregated to the population level as $E\left(q_{1}-q_{0}\right)$ and this represents the ATE (predicted adoption rate under the assumption of full awareness) of exposure. It is important to note that both the outcome and its counterfactual cannot be observed for the same farmer (Diagne and Demont, 2007), therefore $q_{1 i}-q_{0 i}$ cannot be measured. However, awareness is a necessary condition for adoption, hence unaware equals zero (i.e. $\left.q_{0}=0\right)$. This implies adoption impact of farmer $i$ is $q_{1 i}$ and the average adoption impact of exposure is reduced to $E\left(q_{1}\right)$. For the exposed sub-sample $(m=1)$, the mean adoption impact of the aware sub-sample is the conditional expected value $E\left(q_{1} \mid m=1\right)$, which refers to average treatment on the treated (ATT). Similarly, for the unaware sub-sample, the mean adoption impact is $E\left(q_{1} \mid m=0\right)$ and this refers to average treatment on the untreated (ATU) ${ }^{1}$.

From (1), when $q_{0}=0$, the observed adoption outcome reduces to $m q_{1}$ suggesting the observed adoption outcome variable integrates exposure and adoption outcome. This refers to joint awareness and adoption rate (JAA). That is the probability of exposure and adoption of at least one of the SDRP packages. The difference between ATE and JAA is the adoption gap (GAP), indicating the degree to which lack of awareness reduces adoption rate. The GAP (E(q)-E $\left(q_{1}\right)$ ) is usually negative and reduces with increased level of exposure (Kabunga et al. 2012). The difference between mean potential outcome in the aware sub-population and the potential mean adoption outcome in the full population is the population selection bias (PSB). That is the difference between ATT and ATU (PSB=ATT-ATU=E $\left(q_{1} \mid m=1\right)-E$ $\left(q_{1}\right)$ ). PSB indicates the extent of bias in an estimate of adoption rate under full awareness, based on the observed adoption rate of the aware sub-sample.

The ATE estimator draws from the conditional independence $(\mathrm{Cl})$ assumption that postulates that a set of covariates determining exposure when controlled for renders the treatment status $(\mathrm{m})$ independent of the potential outcomes $q_{1}$ and $q_{0}$. Based on the $\mathrm{Cl}$ assumption, parameters of the ATE model can be estimated using parametric, nonparametric and semiparametric methods. In this paper, following Diagne and Demont (2007), the parametric procedures are adopted by formulating a model for the conditional expectation of the observed variables, $\mathrm{q}, \mathrm{x}, \mathrm{m}$ :

$$
E(q \mid x, m=1)=g(x, \beta)
$$

Where: $g$ is a function of observed covariates $x$, determining adoption and a parameter vector $\beta$.

Based on specifications of previous studies (Kathage et al. 2016; Simtowe et al. 2016b), $\beta$ can be estimated through a maximum likelihood technique using observations in the awareness sub-sample with $q$ as dependent and $x$ as independent variable. The estimated $\beta$ parameters are then used to predict values for $q$ in the non-exposure subsample. The average of the predicted values indicates ATE, ATT and ATU, respectively:

$$
\begin{gathered}
A T E=\frac{1}{N} \sum_{i=1}^{N} g\left(x_{i}, \hat{\beta}\right) \\
A T T=\frac{1}{N_{e}} \sum_{i=1}^{N} m_{i} g\left(x_{i}, \hat{\beta}\right) \\
A T U=\frac{1}{N-N_{e}} \sum_{i=1}^{N} g\left(m_{i}-1\right) g\left(x_{i}, \hat{\beta}\right)
\end{gathered}
$$

\footnotetext{
${ }^{1}$ We have changed the notation of ATE1 and ATEO as specified in Diagne, A. \& Demont, M. 2007 to ATT and ATU to be consistent with the impact model estimation.
} 
Where: $N$ is the full sample size and $N_{e}$ is the awareness sub-sample.

Having defined the average treatment effects model to examine adoption rates and determinants of adoption, the endogenous switching regression model is now specified to examine the impact of the technology.

Modelling impacts of SDRP using endogenous switching regression model. The SDRP adoption decision and impacts on productivity and per capita income can be modelled in a two-stage framework. Following Abdulai and Huffman (2014) and Di Falco et al. (2011), let $W^{*}$ be the latent variable that captures the expected benefits of adoption choice with respect to non-adoption. The latent variable can be specified as

$$
W_{i}{ }^{*}=Z_{i} \gamma+\varepsilon_{i} \text { with } W_{i}=\left\{\begin{array}{l}
1 \text { if } W_{i}^{*}>0 \\
0 \text { otherwise }
\end{array}\right.
$$

Where: $W_{i}^{*}$ is a binary variable indicating 1 , for adoption and 0 , for non-adoption. $y$ denote a vector of parameters to be estimated. The assumption here is that farmer $i$ will choose to adopt if there is a positive marginal benefit of adopting the technology and not adopting it. That is $W_{i}{ }^{*}>0$ and zero $(0)$, otherwise. The error term $(\varepsilon)$ with zero mean and constant variance captures measurement errors unobserved to the researcher but observed to the farmer (Abdulai \& Huffman 2014). The $Z$ vector represents variables that affect the expected benefits of adoption and serve as adoption drivers. In the adoption literature, the $Z$ vector has often been attributed to several factors. Some of these factors relate to poor adaptability of technologies to local conditions (Doss 2003), credit constraints (Suri 2011), infrastructure and institutional factors (Chirwa 2005), perceptions of technology characteristics (Adesina and Baidu-Forson 1995; Useche et al. 2009), among others. For a more detailed review of drivers of agricultural technologies, readers are referred to Foster and Rosenzweig (2010). In this paper, the $Z$ vector is associated with land related factors (e.g. fertility and topography), farmer and technology characteristics (Adesina \& Baidu-Forson 1995; Adesina \& Zinnah 1993; Abdulai \& Huffman 2014).

The effects of SDRP adoption on productivity and income per capita could be examined by estimating simple OLS regression of productivity and income where adoption is a dummy. However, Di Falco et al. (2011) noted that such an approach would bias the estimates because of the assumption that adoption is exogenously determined while it could be endogenous. Decision to adopt or not adopt an SDRP may be an issue of self-selection. There could also be fundamental systematic differences between adopters and nonadopters, which must be accounted for. Previous studies (Zackaria et al. 2016; Awotide et al. 2015) have mainly addressed self-selection bias using a propensity score matching (PSM) approach (Rosenbaum \& Rubin 1983). Abdulai and Huffman (2014) pointed out that the PSM model mainly constitutes correcting for unobservables by balancing the observed distributions of covariates across groups of adopters and non-adopters. Therefore, the probit and logit estimates cannot be considered as determinants of adoption. The Endogenous switching regression (ESR) model is a better option as it simultaneously models drivers of adoption and impacts on outcome variables. Lee (1982) developed the ESR model as a generalisation of the Heckman's sample selection model and accounts for unobservables by treating selectivity as an omitted variable problem (Abdulai \& Huffman 2014).

In the context of the SDRP adoption, observed net benefit of farmers choosing to either adopt or not adopt the technology can be specified as a two-regime model:

$$
\begin{aligned}
& Q_{i A}=X^{\prime} \beta_{i A}+\mu_{i A} \text { if } W_{i}=1 \\
& Q_{i N}=X^{\prime} \beta_{i N}+\mu_{i N} \text { if } W_{i}=0
\end{aligned}
$$

Where: $Q_{i A}$ and $Q_{i N}$ are the outcome variables for adopters and non-adopters, respectively, $X^{\prime}$ is a vector of covariates. The vectors $\beta$ in (7) and $Y(6)$ are associated parameters that should be estimated. For identification purposes, a variable in (6) need not be in (7). Following Abdulai and Huffman (2014) and others, we assume that the error terms are trivariate normal distribution with mean vector of zero and the following covariance: 


$$
\operatorname{cov}\left(\varepsilon_{i}, \mu_{i N}, \mu_{i A}\right)=\sum\left(\begin{array}{ccc}
\sigma_{A}^{2} & \sigma_{A N} & \sigma_{A \varepsilon} \\
\sigma_{A N} & \sigma_{N}^{2} & \sigma_{N \varepsilon} \\
\sigma_{A \varepsilon} & \sigma_{N \varepsilon} & \sigma_{\varepsilon}^{2}
\end{array}\right)
$$

Where: variance $\left(\mu_{A}\right)=\sigma_{A}^{2}$, variance $\left(\mu_{N}\right)=\sigma_{N}^{2}$, variance $(\varepsilon)=\sigma_{\varepsilon}^{2}$, covariance $\left(\mu_{A}, \mu_{N}\right)=\sigma_{A N}$, covariance $\left(\mu_{A}, \varepsilon\right)=\sigma_{A \varepsilon}$ and covariance $\left(\mu_{N}, \varepsilon\right)=\sigma_{N \varepsilon}$. Following previous studies (Kotz, 1970; Abdulai and Huffman, 2014), the expected values of the truncated error terms: $\left(\mu_{A} \mid W=1\right)$ and $\left(\mu_{N} \mid W=0\right)$ are given as:

$$
\begin{gathered}
E\left(\mu_{N} \mid W=0\right)=\mathrm{E}\left(\mu_{N} \mid \varepsilon\right) \leq-Z^{\prime} \gamma=\sigma_{N \varepsilon} \frac{-\varphi\left(Z^{\prime} \gamma / \sigma\right)}{1-\varphi\left(Z^{\prime} \gamma / \sigma\right)} \equiv \sigma_{N \varepsilon} \lambda_{N} \\
E\left(\mu_{N} \mid W=0\right)=\mathrm{E}\left(\mu_{N} \mid \varepsilon\right) \leq-Z^{\prime} \gamma=\sigma_{N \varepsilon} \frac{-\varphi\left(Z^{\prime} \gamma / \sigma\right)}{1-\varphi\left(Z^{\prime} \gamma / \sigma\right)} \equiv \sigma_{N \varepsilon} \lambda_{N}
\end{gathered}
$$

Where: $\varphi$ and $\phi$ are the probability density and cumulative distribution function of the standard normal distribution, respectively. The ratio of $\varphi$ and $\phi$ evaluated at $Z^{\prime} \gamma$ refers to the inverse mills ratio $\lambda_{N}$ and $\lambda_{A}$. The selectivity terms are incorporated to account for selectivity bias. The estimation of the model is implemented using full information maximum likelihood (FIML) (Lokshin \& Sajaia 2004). The FIML method is a simultaneous estimation of (6) and (7).

Table 1 - Summary statistics of data

\begin{tabular}{lcc}
\hline & & Total sample \\
\cline { 2 - 3 } Technology adoption dummies & Mean & Standard deviation \\
Land development techniques & & 0.50 \\
Rice cultivation techniques & 0.53 & 0.50 \\
Extension packages & 0.53 & 0.24 \\
Explanatory variables & 0.24 & 8.49 \\
Farming experience (years) & & 1.36 \\
Education (years) & 18.79 & 5.20 \\
Household size & 1.49 & 9.00 \\
Age & 13.00 & 0.35 \\
Sex & 40.00 & 1.18 \\
Total farm size (ha) & 0.14 & 1110 \\
Labour costs & 2.30 & 112.7 \\
Intermediate inputs & 1253.84 & 0.420 \\
Soil fertility (fertile=1) & 194.72 & 0.50 \\
Land topography (flat=1) & 0.77 & 0.47 \\
Land tenure (ownership=1) & 0.48 & \\
Location & 0.68 & 0.48 \\
Sagnarigu & & 0.47 \\
Tamale metro & 0.65 & 0.44 \\
Perception of high yield (1=Yes) & 0.320 & 0.39 \\
Perception of Labour requirement (1=Yes) & 0.266 & 0.45 \\
Perception of lack of capital (1=Yes) & 0.185 & \\
\hline
\end{tabular}

Data descriptive statistics. The data used in this application come from a farm household survey conducted in the Northern region of Ghana in 2014. The aim of the survey was to examine adoption rate, determinants, and impact of the sustainable development of rain-fed lowland rice production (SDRP) on productivity and farmers' income. The survey formed a part of a general study conducted to examine productivity and food security of rice producing households in Ghana. A multistage sampling procedure was adopted to select 222 farmers across three districts in the 2013/2014 cropping season. In the first stage, three districts (Sagnarigu, East Gonja and Tamale) and communities where the SDRP technology was implemented were selected based on stratified random sampling technique. In the 
second stage, simple random sampling technique was used to select farmers based on a list provided by project staff and extension agents from the Ministry of Food and Agriculture.

The survey gathered information on farmers' socio-economic characteristics, awareness and adoption of the SDRP technology. Data were collected on all the three components of the SDRP technology: land development techniques (bunds construction, land levelling and ploughing across slopes); rice cultivation methods (application of fertilizer, seed selection, row drilling and dibbling); and the extension component (farmer group formation, participating in farmer field days and farmer to farmer technology transfer).

In this paper, an adopter is defined as a farmer that uses at least one of the SDRP technology components (Burton et al. 2003). Table 1 presents descriptive statistics of the variables used in the modelling. The sample descriptive statistics provided in Table 1 shows that the average farm size for the full sample is 2.3 hectares and both adopters and nonadopters have similar farm sizes. The average age of farmers in the sample is 40 years, implying a youthful farming population. Farmers also have low educational background, and soil fertility is slightly higher for adopters than non-adopters.

\section{RESULTS AND DISCUSSION}

This paper aims at evaluating the SDRP adoption rates, determinants, and impact on farmer's productivity and income using the ATE adoption framework and the FIML endogenous switching regression model (Lokshin and Sajaia, 2004). Table 2 reports estimates of the ATE model, while Tables 3-5 present the result of the ESR model ${ }^{2}$. The ATE framework examines the role of factors determining exposure and adoption and predicts adoption rates under complete exposure. The variables in both the exposure and adoption model are slightly different because in the ATE framework, with conditional independence assumption, factors in the awareness and adoption models can differ (Kathage et al. 2016). The discussion begins with adoption rates and conclude with the impact of the SDRP adoption on farmers' productivity and income.

Estimates from the ATE adoption model. The estimated results of the ATE model to predict adoption rates with and without information constraints (exposure to the technology as a measure of information constraint) are presented in Table 2. The upper part of the table shows predicted adoption rates when complete awareness is assumed, and the lower part of the table shows actual observed exposure and adoption rates.

JAA is the observed adoption rate, ATT is the observed adoption rate among exposure sub-sample and ATE is the predicted adoption rate with complete exposure. The estimated results show that the ATE, which determines demand of the technology (combined technology ${ }^{3}$ ) is $59 \%$ compared to $55 \%$ actual adoption rate generated from the standard probit model. The difference is what is described in the GAP (non-exposure or awareness bias) as $4 \%$. This implies that SDRP adoption would increase from $55 \%$ to $59 \%$ if all farmers were fully aware of the technology instead of the observed $90 \%$ awareness rate. The increase in adoption rate for awareness correction is $4 \%$ and this figure is quite consistent with previsous studies. For instance, Simtowe et al. (2016a) estimated an adoption rate of $39 \%$ for pigeon pea adoption in Malawi. There was, however, a $2 \%$ improvement in the value when adoption was adjusted for awareness bias. Diagne and Demont (2007) also estimated adoption rate for NERICA in Cote Devoir as 37\%, after adjusting for awareness bias. Furthermore, Kathage et al. (2016) estimated adoption rates for hybrid maize variety in Tanzania and found upon accounting for awareness bias that adoption rate was $50 \%$.

Considering the individual SDRP components, the results show that adoption rate of the land development technique (L1) is higher (58\%), followed by L2-rice cultivation technique (56\%) and lastly, extension component (L3), which is least adopted (26\%). The corresponding population adoption gaps are $5 \%, 4 \%$, and $1 \%$ for L1, L2 and L3, respectively. Furthermore, the results show that adoption rates for non-exposed sub-population are lower

\footnotetext{
${ }^{2}$ It is important to know that although the results are reported separately, model estimation was conducted simultaneously as that has been described as efficient, yielding unbiased estimates (Diagne \& Demont 2007).

${ }^{3}$ Choosing either one of the technology components.
} 
compared with the exposed sub-population. This finding is contrary to Diagne and Demont (2007) study outcome where there was no difference between adoption rates for aware and unaware sub-population.

Table 1 - Predicted adoption rate of modern rice production practices

\begin{tabular}{|c|c|c|c|c|}
\hline \multirow{2}{*}{ Parameters } & \multirow{2}{*}{$\begin{array}{c}\text { All technology } \\
\text { components } \\
\text { Total }\end{array}$} & \multicolumn{3}{|c|}{ Individual technology components } \\
\hline & & L1 & L2 & L3 \\
\hline \multicolumn{5}{|l|}{ ATE-corrected population estimates } \\
\hline Predicted adoption rate in the full population (ATE) & $0.590^{\star \star \star}$ & $0.579^{\star \star \star}$ & $0.562^{\star * \star}$ & $0.254^{\star * *}$ \\
\hline Predicted adoption rate in the sub-population (ATT) & $0.610^{\star \star \star}$ & $0.586^{* \star *}$ & $0.584^{\star \star *}$ & $0.269^{\star \star *}$ \\
\hline Predicted adoption rate in the unaware population (ATU) & $0.441^{\star * \star}$ & $0.515^{\star \star \star}$ & $0.365^{\star \star \star}$ & $0.131^{\star \star \star}$ \\
\hline Joint awareness and adoption rate (JAA) & $0.548^{* * *}$ & $0.528^{* * *}$ & $0.526^{\star * *}$ & $0.240^{* * *}$ \\
\hline Population adoption gap (GAP) & $-0.044^{\star * *}$ & $-0.051^{\star \star *}$ & $-0.036^{\star * *}$ & $-0.014^{\star \star *}$ \\
\hline $\begin{array}{l}\text { Population selection bias (PSB) } \\
\text { Observed sample estimates }\end{array}$ & $0.017^{\star \star \star}$ & $0.007^{\star \star \star}$ & $0.022^{\star \star *}$ & $0.015^{\star * *}$ \\
\hline $\begin{array}{l}\text { Ubserved sample estımates } \\
\text { Awareness rate }\left(N_{e} / N\right)\end{array}$ & $0.909^{* * *}$ & $0.901^{* * *}$ & $0.901^{\star * *}$ & $0.893^{\star * *}$ \\
\hline Adoption rate $(\mathrm{Na} / \mathrm{N})$ & $0.550^{\star * *}$ & $0.527^{\star \star *}$ & $0.527^{\star \star *}$ & $0.239^{* * *}$ \\
\hline Adoption rate among aware subsample ( $\mathrm{Na} / \mathrm{Ne})$ & $0.610^{\star \star *}$ & $0.585^{\star * *}$ & $0.585^{\star * *}$ & $0.268^{\star * *}$ \\
\hline
\end{tabular}

Note: ${ }^{*}{ }^{* *},{ }^{* * *}$ indicate significance at $10 \%, 5 \%$ and $1 \%$ respectively. $L 1=$ Land development technique, L2=Rice cultivation techniques, $L 3=$ Extension package.

Comparing the estimated adoption rate to previous rates reported in the literature shows an improvement in adoption of new technologies in Ghana. However, the estimated adoption rate (59\%) is still low, suggesting low adoption may not necessarily be a function of information constraint. It is, therefore, important to examine the determinants of SDRP adoption to inform policy makers on the measures that drive adoption.

Table 3 - Parameter estimates of SDRP adoption and yield per hectare equation

\begin{tabular}{|c|c|c|c|}
\hline & \multicolumn{3}{|c|}{ Endogenous switching regression } \\
\hline & Selection & Adoption $=1$ & Adoption $=0$ \\
\hline Variable & Adoption & Yield per hectare & Yield per hectare \\
\hline Constant & $-2.838^{\star \star \star}$ & $15.129^{\star \star *}$ & $8.513^{\star \star *}$ \\
\hline Farming experience (years) & 0.025 & 0.117 & -0.023 \\
\hline Education (years) & 0.089 & -0.251 & 0.015 \\
\hline Household size & -0.003 & -0.047 & -0.015 \\
\hline Age & -0.022 & 0.127 & 0.007 \\
\hline Sex & 0.421 & $3.397^{\star \star \star}$ & 1.073 \\
\hline Total farm size (ha) & 0.005 & $-4.929^{\star \star *}$ & $-1.335^{\star \star \star}$ \\
\hline Labour costs & 0.000 & $0.002^{* * *}$ & $0.000^{*}$ \\
\hline Intermediate inputs & $0.005^{\star \star *}$ & 0.009 & 0.005 \\
\hline Land tenure (ownership $=1$ ) & $1.537^{\star *}$ & 2.834 & -0.019 \\
\hline Soil fertility (fertile $=1$ ) & $0.710^{\star \star}$ & 1.879 & 1.199 \\
\hline Land topography (flat=1) & 0.341 & $-2.151^{* *}$ & 1.027 \\
\hline Sagnarigu & 0.772 & -1.688 & -1.306 \\
\hline Tamale Metro & -0.978 & -2.106 & -0.299 \\
\hline Perception of higher yield ( $1=$ Yes) & $3.333^{* * *}$ & - & - \\
\hline Labour requirement (1=Yes) & -0.394 & - & - \\
\hline Lack of capital (1=Yes) & -0.251 & - & - \\
\hline IMR (Exposure) & $1.453^{\star * *}$ & - & - \\
\hline Ln sigma 1 (adopters) & - & $1.786^{\star \star \star}$ & - \\
\hline Ln sigma 2 (non-adopters) & - & - & $0.936^{\star * *}$ \\
\hline Rho1 (adopters) & - & $-1.142^{\star * *}$ & - \\
\hline Rho2 (non-adopters) & - & - & 0.165 \\
\hline Number of observations & 222 & 122 & 100 \\
\hline Log likelihood & -701.07 & - & - \\
\hline$P>c h i$ & 0.000 & - & - \\
\hline
\end{tabular}

Note: ${ }^{*}{ }^{* *},{ }^{* *}$ indicate significance at $10 \%, 5 \%$ and $1 \%$ respectively. IMR=Inverse mills ratio.

Estimates from endogenous switching regression model. The selection equation model estimates reported in the second column of Tables 3 and 4 show the main drivers of SDRP adoption. From the estimated coefficients, farmers with very fertile cultivable lands have a high probability to adopt SDRP, suggesting that farmers consider land quality factors in technology adoption decisions. A similar finding was reported in Abdulai and Huffman (2014) study on adoption of water conservation technology in Ghana. The coefficient of the land 
ownership variable is also positive and significantly different from zero, suggesting that farmers with outright land ownership have a high probability to adopt new technologies, compared to those with other ownership arrangements. This finding confirms Ogada et al. (2014) study outcome of the effects of tenure security on adoption of new agricultural technologies.

Feder et al. (1985) pointed out that land tenure may indirectly be associated with access to credit, input markets, product market and technical information mainly because in some parts of the world, e.g. Ghana, land is deemed very valuable and may be used as collateral to secure a loan for production. Therefore, land ownership enables the farmer to secure such a facility, which otherwise may be difficult to attain. There are also other varying reports of the effects of land ownership on adoption, where owners have a high tendency to adopt new technologies compared with tenants and the finding of this study falls within this theme of literature (Feder et al. 1985). Also, although not all the technology characteristics are significant, the estimated coefficients reveal that perception of high yield affects the probability of SDRP adoption. Similar findings have been reported in previous studies about the effects of technology characteristics on farmers' adoption decisions (Adesina \& BaiduForson 1995; Adesina \& Zinnah 1993).

Determinants of farm productivity (yield) and income. The estimation of the impact model requires that at least one variable in the selection equation does not appear in the outcome equation (Abdulai \& Huffman 2014). In the yield and income specifications, farmers' perceptions regarding yield, labour requirement, and capital requirement were excluded from the outcome equation. The estimates presented in the third and fourth columns of Tables 4 and 5 accounts for the endogenous switching in the yield and income functions, respectively.

Firstly, the estimated coefficients of the correlation terms are significant, suggesting that sample selection occurred in the adoption of SDRP. The negative sign (rho 1) indicates a positive selection bias (comparative advantage in adoption), suggesting that farmers with above average yields and income have a higher probability of adopting the SDRP. The findings are consistent with Abdulai and Huffman (2014) study outcome on adoption of water conservation technology in Ghana. They are, however, contrary to Suri (2011), who observed a negative selection bias in technology adoption. Exposure bias was also accounted for in the ESR model by introducing inverse Mills ratio (IMR) from a probit exposure model as a proxy. The estimated coefficient on the IMR is positive and significant indicating that exposure bias is apparent in the ESR model, failure to account for which may result in upward bias in estimates.

The results also indicate that among adopters of the technology, labour usage, farm size and land topography explain higher yields (Table 3). However, larger farm size seems to have a negative effect on yield for both adopters and non-adopters. This finding indicates that larger farms obtain lower yield compared to smaller farms, a finding that supports inverse farm size productivity relationship in developing countries (Abdulai and Huffman, 2014). The results also show among the adopters that female headed households are more productive compared to male headed households (Table 3). Regarding income per capita (Table 4), results show among adopters that farm experience increases incomes, while land topography (flat surface) decreases farm income. The estimated coefficients also reveal the effects of household size and topography on the income of non-adopters.

Impact of SDRP on farm productivity (yield) and income. The estimates of the impact of adoption on yield and income per capita are reported in Table 5. The estimated yield per hectare of farm households that adopted the SDRP is about 13 bags, while it is 7 bags for non-adopters. However, the mean comparison is misleading because of the impact of other characteristics such as sample selection bias. The last three columns of Table 5 report results adjusted for selection bias arising from the fact that adopters and non-adopters may be systematically different. From the estimated result, adoption of the SDRP significantly increases yield and income per capita. Specifically, the causal effect of adoption on yield is 5.35 bags per hectare, representing about $76 \%$ increase in the average yield per hectare of non-adopters. Similarly, adoption increases income per capita by $77 \%$ from 3.37 Ghana Cedis (GHS) to 6.23 GHS. 
Table 4 - Endogenous switching regression results for adoption and impact of adoption on farmers' income per capita

\begin{tabular}{|c|c|c|c|}
\hline & \multicolumn{3}{|c|}{ Endogenous switching regression } \\
\hline & Selection & Adoption $=1$ & Adoption $=0$ \\
\hline Variable & Adoption & Per capita income & Per capita income \\
\hline Constant & $-3.040^{* \star *}$ & $7.19^{\star *}$ & 0.235 \\
\hline Farming experience (years) & 0.017 & $0.136^{*}$ & -0.041 \\
\hline Education (years) & 0.101 & -0.099 & -0.234 \\
\hline Household size & -0.010 & -0.040 & $-0.086^{*}$ \\
\hline Age & -0.009 & -0.065 & 0.028 \\
\hline Sex & 0.272 & -0.065 & -0.285 \\
\hline Total farm size (ha) & -0.061 & 0.696 & $0.539^{\star \star \star}$ \\
\hline Labour costs & 0.000 & $0.002^{\star * *}$ & 0.000 \\
\hline Intermediate inputs & $0.004^{\star \star \star *}$ & 0.001 & $0.009^{\star \star *}$ \\
\hline Land tenure (ownership=1) & $1.551^{\star *}$ & -1.202 & 2.066 \\
\hline Soil fertility (fertile $=1$ ) & $0.931^{* * *}$ & 0.120 & 0.479 \\
\hline Land topography (flat $=1$ ) & 0.382 & $-3.822^{* * *}$ & $-2.606^{* * *}$ \\
\hline Sagnarigu & 0.837 & -0.347 & 1.175 \\
\hline Tamale Metro & -0.976 & -0.471 & -0.038 \\
\hline Perception of higher yield ( $1=$ Yes) & $2.681^{* * *}$ & - & - \\
\hline Labour requirement ( $1=$ Yes) & 0.231 & - & - \\
\hline Lack of capital & -0.369 & - & - \\
\hline IMR (awareness) & $1.463^{* * *}$ & - & - \\
\hline Ln sigma 1 (adopters) & - & $1.447^{\star * *}$ & - \\
\hline Ln sigma 2 (non-adopters) & - & - & $0.729^{\star * \star}$ \\
\hline Rho1 (adopters) & - & $-0.643^{\star * *}$ & - \\
\hline Rho2 (non-adopters) & - & - & 0.198 \\
\hline Number of observations & 222 & 122 & 100 \\
\hline Log likelihood & - & -271.105 & - \\
\hline$P>$ chi & - & 0.000 & - \\
\hline
\end{tabular}

Note: *, ${ }^{* *},{ }^{* *}$ indicate significance at $10 \%, 5 \%$ and $1 \%$ respectively. IMR=Inverse mills ratio.

Table 5 - Impact of technology adoption on yield

\begin{tabular}{|c|c|c|c|c|c|}
\hline & \multicolumn{2}{|c|}{ Decision stage (mean outcome) } & \multicolumn{3}{|c|}{ Treatment effects (FIML model) } \\
\hline Yield/ bags/ha & To adopt & Not to adopt & ATE & ATT & ATU \\
\hline $\begin{array}{l}\text { Farmers that adopted } \\
\text { Income/capita }\end{array}$ & 13.25 & 7.00 & $5.354^{\star \star \star}$ & $5.818^{\star \star \star}$ & $4.788^{\star \star \star}$ \\
\hline Farmers that adopted & 6.23 & 3.37 & $2.600^{* \star *}$ & $2.713^{\star \star \star}$ & $2.463^{\star \star \star}$ \\
\hline
\end{tabular}

These findings are consistent with previous study outcomes that adoption of agricultural technologies improves farm productivity and income (Abdulai \& Huffman, 2014; Zackaria et al. 2016; Bravo-Ureta et al. 2006; Manda et al. 2016; Kassie et al. 2015; Abdulai 2016a; Zeng et al. 2015).

\section{CONCLUSION}

Over the years, it has long been understood that adoption and use of new agricultural technologies in sub-Sahara Africa (SSA) improve agricultural productivity and welfare of farm households. However, adoption and use of new agricultural technologies in SSA is very low. This puzzle of low adoption has become a major research question for most agricultural economists. With several adoption drivers identified over the years, new technologies introduced have sought to address some of these factors. The critical question, therefore is to what extent has modifications in these agricultural technologies influenced adoption of new agricultural technologies in SSA. The objective of this paper therefore was to contribute to the debate on farmer adoption in developing countries through a socio-economic analysis of agricultural technology adoption in Ghana. Specifically, adoption rates, adoption drivers and effects of adoption of the sustainable rain-fed low-land rice production technology on farm productivity and income. The average treatment effects model that addresses exposure bias was employed in estimating adoption rates while the endogenous switching regression model was used to account for sample selection bias in the impact evaluation model. 
The empirical results show an SDRP adoption intensity of 55 percent under exposure bias. After accounting for exposure bias, the value increased to 59 percent. Although this value gives an indication of slight improvement over previous adoption rates reported in the literature (Pingali, 2007), the value is still low compared with values reported in many Asian countries (Pingali, 2012). Therefore, the question of low adoption to some extent persists after accounting for information constraint. It, therefore, suffices to note that information constraint may not be key barrier to adoption in our sample. This finding is in keeping with Kathage et al. (2016) that information constraint may not be the rationale for low adoption in SSA.

On the drivers of SDRP adoption, the findings indicate that among other things, land tenure, the perception of higher yield component of new technologies and soil fertility are the factors identified to drive farmer's adoption. In the recent literature, farmers' perception of technology characteristics has proved vital for adoption, and this finding confirms previous study outcomes of the effects of perceptions of technology characteristics (Adesina and Baidu-Forson, 1995; Adesina and Zinnah, 1993). Given the low adoption rate reported in this study and previous studies (Pingali 2012), it may suffice to consider issues relating to farmers cognitive, social and behavioural patterns on adoption and use of new technologies. Another, useful area to consider would be the application of panel adoption data, instead of the cross-sectional data used in most empirical studies.

On the impact of the SDRP adoption, the results indicate a possible sample selection bias, therefore modelling outcome equations without considering adoption decisions, would affect estimated results and possible policy conclusions (Abdulai \& Huffman, 2014). This is mainly because the SDRP may not have the same effect on both adopters and nonadopters. In addition, the estimated results reveal a positive selection bias for both rice yield and income, suggesting that more productive and wealthy farmers tend to adopt the SDRP. On the impact of adoption on farm productivity and income, results show the causal effects of adoption were to increase rice yields of about $76 \%$ and income per capita of about $77 \%$. The findings suggest that adoption of SDRP can significantly increase productivity and farm incomes. Furthermore, the findings reiterate the role of new agricultural technologies on agricultural productivity in developing countries (Abdulai \& Huffman 2014).

Overall, the findings of this study have policy implications for the introduction of new agricultural technologies in developing countries. The findings suggest improvement in land quality and ownership in developing countries would ensure increased adoption of new agricultural technologies. In addition, it is also important to consider technology characteristics that farmers would value to improve adoption and use of new agricultural technologies. This could be achieved through a stated preference approach, specifically discrete choice experiment.

\section{STATEMENT OF INTERESTS CONFLICT}

The author declares that there are no conflicts of interest.

\section{REFERENCES}

1. Abdulai, A. \& Huffman, W. (2014). The adoption and impact of soil and water conservation technology: An endogenous switching regression application. Land Economics, 90, 26-43.

2. Abdulai, A. N. (2016). Impact of conservation agriculture technology on household welfare in Zambia. Agricultural Economics.

3. Adesina, A. A. \& Baidu-Forson, J. (1995). Farmers' perceptions and adoption of new agricultural technology: evidence from analysis in Burkina Faso and Guinea, West Africa. Agricultural economics, 13, 1-9.

4. Adesina, A. A. \& Zinnah, M. M. (1993). Technology characteristics, farmers' perceptions and adoption decisions: A Tobit model application in Sierra Leone. Agricultural economics, 9, 297-311. 
5. Alene, A. D. \& Manyong, V. (2007). The effects of education on agricultural productivity under traditional and improved technology in northern Nigeria: an endogenous switching regression analysis. Empirical economics, 32, 141-159.

6. Angelucci, F., Asante-Poku, A. \& Anaadumba, P. (2013). Analysis of incentives and disincentives for rice in Ghana. Technical notes series, MAFAP, FAO, Rome.

7. Awotide, B. A., Alene, A. D., Abdoulaye, T. \& Manyong, V. M. (2015). Impact of agricultural technology adoption on asset ownership: the case of improved cassava varieties in Nigeria. Food Security, 7, 1239-1258.

8. Besley, T., Coate, S. \& Loury, G. (1993). The economics of rotating savings and credit associations. The American Economic Review, 792-810.

9. Brave, S. \& Walstrum, T. (2014). Estimating marginal treatment effects using parametric and semiparametric methods. Stata Journal, 14, 191-217.

10. Burton, M., Rigby, D. \& Young, T. (2003). Modelling the adoption of organic horticultural technology in the UK using duration analysis. Australian Journal of Agricultural and Resource Economics, 47, 29-54.

11. Chirwa, E. W. (2005). Adoption of fertilizer and hybrid seeds by smallholder maize farmers in Southern Malawi. Development Southern Africa, 22, 1-12.

12. Conley, T. \& Udry, C. (2001). Social learning through networks: The adoption of new agricultural technologies in Ghana. American Journal of Agricultural Economics, 83, 668673.

13. Di Falco, S., Veronesi, M. \& Yesuf, M. (2011). Does adaptation to climate change provide food security? A micro-perspective from Ethiopia. American Journal of Agricultural Economics, 93, 829-846.

14. Diagne, A. \& Demont, M. (2007). Taking a new look at empirical models of adoption: Average treatment effect estimation of adoption rates and their determinants. Agricultural Economics, 37, 201-210.

15. Doss, C. R. (2003). Understanding farm level technology adoption: lessons learned from CIMMYT's micro surveys in Eastern Africa.

16. Feder, G., Just, R. E. \& Zilberman, D. (1985). Adoption of agricultural innovations in developing countries: A survey. Economic development and cultural change, 33, 255298.

17. Foster, A. D. \& Rosenzweig, M. R. (1995). Learning by doing and learning from others: Human capital and technical change in agriculture. Journal of political Economy, 11761209.

18. Foster, A. D. \& Rosenzweig, M. R. (2010). Microeconomics of technology adoption. Annual review of Economics, 2.

19. Kabunga, N. S., Dubois, T. \& Qaim, M. (2012). Heterogeneous information exposure and technology adoption: The case of tissue culture bananas in Kenya. Agricultural Economics, 43, 473-486.

20. Kassie, M., Jaleta, M., Shiferaw, B., Mmbando, F. \& Mekuria, M. (2013). Adoption of interrelated sustainable agricultural practices in smallholder systems: Evidence from rural Tanzania. Technological forecasting and social change, 80, 525-540.

21. Kassie, M., Teklewold, H., Marenya, P., Jaleta, M. \& Erenstein, O. (2015). Production risks and food security under alternative technology choices in Malawi: Application of a multinomial endogenous switching regression. Journal of Agricultural Economics, 66, 640-659.

22. Kathage, J., Kassie, M., Shiferaw, B. \& Qaim, M. (2016). Big constraints or small returns? Explaining nonadoption of hybrid maize in Tanzania. Applied Economic Perspectives and Policy, 38, 113-131.

23. Kotz, S. 1970. Distributions in Statistics: Continuous Univariate Distributions.

24. Lee, L.-F. (1982). Some approaches to the correction of selectivity bias. The Review of Economic Studies, 49, 355-372.

25. Lokshin, M. \& Sajaia, Z. (2004). Maximum likelihood estimation of endogenous switching regression models. Stata Journal, 4, 282-289. 
26. Manda, J., Alene, A. D., Gardebroek, C., Kassie, M. \& Tembo, G. (2016). Adoption and Impacts of Sustainable Agricultural Practices on Maize Yields and Incomes: Evidence from Rural Zambia. Journal of Agricultural Economics, 67, 130-153.

27. Mumuni, E. \& Oladele, O. I. (2012). Farmers' assessment of Donor support for Rain-fed Lowland Rice Production in Ashanti and Northern Regions in Ghana. Life Science Journal, 9, 377-381.

28. MOFA (2009). National Rice Development Strategy. In: MOFA (ed.). Accra, Ghana: Government Publications. Accessed on January 23 2019.

29. Ogada, M. J., Mwabu, G. \& Muchai, D. (2014). Farm technology adoption in Kenya: a simultaneous estimation of inorganic fertilizer and improved maize variety adoption decisions. Agricultural and food economics, 2, 1.

30. Oteng, J. (1997). Rice production and development in Ghana. Bulletin de la Commission Internationale du Riz (FAO); Noticiario de la Comision Internacional del Arroz (FAO).

31. Owusu Coffie, R., Burton, M. P., Gibson, F. L. \& Hailu, A. (2016). Choice of Rice Production Practices in Ghana: A Comparison of Willingness to Pay and Preference Space Estimates. Journal of Agricultural Economics, 67, 799-819.

32. Pingali, P. (2007). Agricultural mechanization: adoption patterns and economic impact. Handbook of agricultural economics, 3, 2779-2805.

33. Pingali, P. L. \& Evenson, R. E. (2010). Handbook of agricultural economics, Elsevier.

34. Rosenbaum, P. R. \& Rubin, D. B. (1983). The central role of the propensity score in observational studies for causal effects. Biometrika, 70, 41-55.

35. Simtowe, F., ASFAW, S. \& ABATE, T. (2016a). Determinants of agricultural technology adoption under partial population awareness: the case of pigeonpea in Malawi. Agricultural and Food Economics, 4, 7.

36. Simtowe, F., Asfaw, S. \& Abate, T. (2016b). Determinants of agricultural technology adoption under partial population awareness: the case of pigeonpea in Malawi. Agricultural and Food Economics, 4, 1.

37. Smith, J. A. \& Todd, P. E. (2005). Does matching overcome LaLonde's critique of nonexperimental estimators? Journal of econometrics, 125, 305-353.

38. Suri, T. (2006). Selection and Comparative Advantage in Technology Adoption.

39. Suri, T. (2011). Selection and comparative advantage in technology adoption. Econometrica, 79, 159-209.

40. Useche, P., Barham, B. L. \& Foltz, J. D. (2009). Integrating technology traits and producer heterogeneity: A mixed-multinomial model of genetically modified corn adoption. American Journal of Agricultural Economics, 91, 444-461.

41. Zackaria, A., Ansah, I. K., Abdulai, S. \& Donkoh, S. (2017). The determinants and effects of jica rice technology adoption in the Sagnarigu District of the Northern Region, Ghana. UDS International Journal of Development, 3, 1-12. 